\title{
Treatment of Simulated Waste Water Containing Methyl Red by Advanced Oxidation Process
}

\section{Mateen Ahmad ${ }^{\star}$ and Ammad Shahid Minhas}

Department of Chemical Engineering, University of the Punjab, Lahore, Pakistan

*Corresponding author: Mateen Ahmad, Department of Chemical Engineering, University of the Punjab, Lahore, Pakistan, Tel: 0092-55-9201222; E-mail: mateencheema63@gmail.com

Received date: Dec 11, 2017; Accepted date: Dec 20, 2017; Published date: Dec 22, 2017

Copyright: ( 2017 Ahmad M, et al. This is an open-access article distributed under the terms of the Creative Commons Attribution License, which permits unrestricted use, distribution, and reproduction in any medium, provided the original author and source are credited.

\begin{abstract}
Advanced oxidation process is one of the promising technologies to eliminate the toxic pollutants, total organic contents etc. from waste water. Attempts are being made from previous few years on treatment of waste water using various advanced oxidation treatment methods like Fenton process. In Fenton process the reaction of $\mathrm{FeSO}_{4}$ and Fenton reagent $\mathrm{H}_{2} \mathrm{O}_{2}$ at low $\mathrm{pH}$, involves the decomposition of Fenton reagent and results in $\mathrm{Fe}^{2+}$ generation, produce hydroxyl radicals which oxidize tough to decompose organics compounds due to its high oxidizing ability, in very short time. In this study, the application of Fenton process for the degradation of organic component from the water contaminated with methyl red an azo dye, has been inspected to present the assessment of Fenton process in waste water treatment. Concentration of Fenton reagent, ferrous sulphate and other process parameters like contact time and $\mathrm{PH}$ has been studied. $\mathrm{H}_{2} \mathrm{SO}_{4}$ and $\mathrm{NaOH}$ solution is used for $\mathrm{pH}$ adjustments. Different combination of experiments to check the COD removal, respect to the doses of $\mathrm{H}_{2} \mathrm{O}_{2}$ and $\mathrm{FeSO}_{4}$ has been performed. The optimum doses of which are $3.5 \mathrm{ml}$ and $0.50 \mathrm{gm}$ respectively, the best result $(81.1 \%$ reduction) is obtained at $\mathrm{pH}$ of $3.0 \pm 0.2$, and reaction time of $30 \mathrm{~min}$, and it is also proved that Fenton process is inefficient in alkaline and neutral medium.
\end{abstract}

Keywords: Oxidation process; Water treatment; Methyl red

\section{Introduction}

Around seventy percent of earth's surface is covered with water. For human consumption, there is only $1 \%$ of total water resources. The water will be very scare soon, looking at the world's population increase rate. Human behavior of using the water is not going to help to overcome this problem, misuse of watering being reported every day and on all forum including the forms of its miss use, and it appears by looking at the wasteful manners of humans mainly in emerging countries where the charts, point lack and scarcity of this resource [1]. The industries and commerce in the rush of profit are spending less or no time and money to get rid of effluent and on effluent treatment their action $s$ are only not polluting the nearby streams but the water underneath the ground as well. Supervision and strict legislation must make certain that the waste-water and effluent is being treated per the environmental concern and laws. Reducing the damages caused to the environment by polluted streams, for effective and proper disposal of polluted streams, efficient and low-cost oxidation processes can be useful. Each production line has its waste water its own effluent, individually of which having its own composition and designated treatment process. Large amount of effluent is being generated by numerous types of factories and industries. When these polluted streams from different production lines are discharged, or disposed in the natural resources by in efficient treatment or untreated, creates severe and serious environmental concerns and problems as per attractive cost efficiency and removal of organic matter, biological methods of waste water treatment are applied throughout, but these methods do not remove all kind matter causing pollution and is not effective on remedial of different types of effluents'. Ensuring the proper and safe discarding of waste water is the application of successful and efficient process removal of toxic component is not the only part, the removal of each content causing environmental concern is of main importance and this principle and it is mandatory now to make it certain that both must be took in consideration for the indicated treatment $[2,3]$.

\section{Materials and Methods}

Methyl red M.W 291.0 from Aldrich Chemical, $\mathrm{H}_{2} \mathrm{O}_{2}$ (35\% from $\mathrm{BDH}), \mathrm{FeSO}_{4}$ and Ferrous ammonium sulphate (from Riedel-de-Haen) is used.

Potassium dichromate and standard solution of $\mathrm{NaOH}$ and $\mathrm{H}_{2} \mathrm{SO}_{4}$ is used for $\mathrm{pH}$ adjustment, distilled water is used to make the solutions.

Boiling the water sample in the mixture of $\mathrm{H}_{2} \mathrm{SO}_{4}$ and chromic acid, results in the oxidization of maximum amount of the organic matter. The waste water specimen is refluxed in that acidic solution, the remaining unreduced chromic acid $\left(\mathrm{K}_{2} \mathrm{Cr}_{2} \mathrm{O}_{7}\right)$ is titrated with Mohr's Salt (FAS) solution after the digestion in reflux apparatus, in this way the quantity of chromic acid consumed is measured and the matter which is oxidable (in the terms of $\mathrm{O}_{2}$ equivalent) is determined. Two hours is the standard time of reflux which can be reduced if the results of reduced reflux time depict the same results, that of $2 \mathrm{hrs}$. reflux time [1-11].

\section{Experiment procedure}

- Add the known amount of water sample in the reflux flask.

- Slowly add $5 \mathrm{ml}$ of $\mathrm{H}_{2} \mathrm{SO}_{4}$ reagent.

- Add known amount of $\mathrm{K}_{2} \mathrm{Cr}_{2} \mathrm{O}_{7}$, mix the contents.

- Place the condenser and turn on the cooling water. 
Citation: Ahmad M, Minhas AS (2017) Treatment of Simulated Waste Water Containing Methyl Red by Advanced Oxidation Process. J Adv

Page 2 of 3

- Avoiding the loss of any volatile materials add known amount of $\mathrm{H}_{2} \mathrm{SO}_{4}$ little by little.

- Put the assembly to the heating plate or iso-mantle and set the temperature to $150^{\circ} \mathrm{C}$.

- Cover the open end of the condenser with beaker to avoid contamination from the outside.

- Reflux the mixture for two hours and cool it to room temperature.

- For titration fill the burette with FAS solution.

- Transfer the contents of refluxing flask to conical flask.

- Add 2-4 drops of Ferron indicator the Colour changes to blue green.

- Titrate with FAS solution the end of titration is appearance of reddish brown Colour.

- The same procedure is adopted by using water instead of specimen for calculations.

\section{Results}

Effect of $\mathrm{FeSO}_{4}$ dosage on COD removal by Fenton process

\begin{tabular}{|l|l|l|l|l|}
\hline $\mathrm{H}_{2} \mathrm{O}_{2}(\mathrm{ml})$ & \multirow{2}{*}{$\mathrm{FeSO}_{4}(\mathrm{gm})$} & \multicolumn{2}{|l|}{ COD $\mathrm{mg} / \mathrm{l}$} & \multirow{2}{*}{ Removal \% } \\
\cline { 3 - 4 } & & Initial & Final & \\
\hline 0.5 & 0.50 & 838 & 374.4 & 55.34 \\
1.5 & 0.50 & 838 & 310.4 & 62.97 \\
2.5 & 0.50 & 838 & 214.4 & 74.42 \\
3.5 & 0.50 & 838 & 158.4 & 81.1 \\
5 & 0.50 & 838 & 182.4 & 78.24 \\
7 & 0.50 & 838 & 174.4 & 79.19 \\
\hline
\end{tabular}

Table 1: Effect of $\mathrm{FeSO}_{4}$ on COD removal.

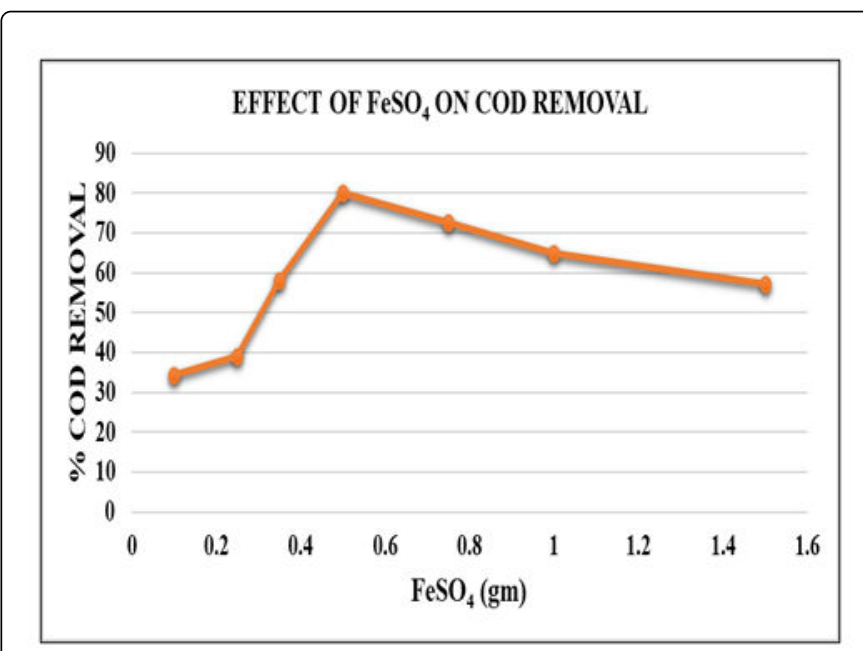

Figure 1: Effect of $\mathrm{FeSO}_{4}$ on COD removal.

Effect of $\mathrm{FeSO}_{4}$ dosage on COD removal by Fenton process is illustrated in Table 1 and Figure 1.

\section{Effect of $\mathrm{H}_{2} \mathrm{O}_{2}$ dosage on COD removal by Fenton process}

\begin{tabular}{|l|l|l|l|l|}
\hline \multirow{2}{*}{$\mathbf{H}_{2} \mathbf{O}_{2}(\mathbf{m l})$} & \multirow{2}{*}{ FeSO $_{4}(\mathbf{g m})$} & \multicolumn{2}{|c|}{ COD mg/l } & \multirow{2}{*}{ Removal \% } \\
\cline { 3 - 5 } & & Initial & Final & \\
\hline 3.5 & 0.1 & 838 & 550.4 & 34.35 \\
3.5 & 0.25 & 838 & 510.4 & 39.12 \\
3.5 & 0.35 & 838 & 350.4 & 57.25 \\
3.5 & 0.50 & 838 & 158.4 & 81.1 \\
3.5 & 0.75 & 838 & 230.4 & 72.50 \\
3.5 & 1.0 & 838 & 294.4 & 64.88 \\
3.5 & 1.5 & 838 & 358.4 & 58.2 \\
\hline
\end{tabular}

Table 2: Effect of $\mathrm{H}_{2} \mathrm{O}_{2}$ on COD removal.

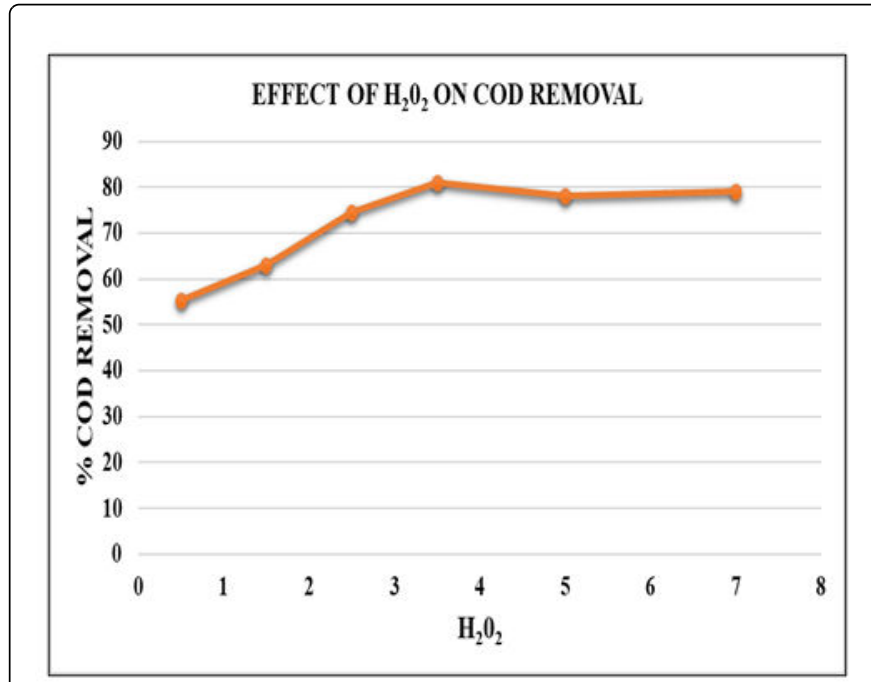

Figure 2: Effect of $\mathrm{H}_{2} \mathrm{O}_{2}$ on COD removal.

Effect of $\mathrm{H}_{2} \mathrm{O}_{2}$ dosage on COD removal by Fenton process is illustrated in Table 2 and Figure 2.

\section{Effect of $\mathrm{pH}$ on COD removal by Fenton process}

\begin{tabular}{|c|c|c|c|c|}
\hline \multirow{2}{*}{$\mathrm{H}_{2} \mathbf{O}_{2}(\mathrm{ml})$} & \multirow{2}{*}{$\begin{array}{l}\text { pH of } \\
\text { sample }\end{array}$} & \multicolumn{2}{|c|}{ COD mg/l } & \multirow{2}{*}{ Removal \% } \\
\hline & & Initial & Final & \\
\hline 3.5 & 2.0 & 838 & 198.4 & 76.38 \\
\hline 3.5 & 3.0 & 838 & 158.4 & 81.1 \\
\hline 3.5 & 4.5 & 838 & 238.4 & 71.61 \\
\hline 3.5 & 6.0 & 838 & 382.4 & 54.38 \\
\hline 3.5 & 8 & 838 & 486.4 & 41.98 \\
\hline
\end{tabular}

Table 3: Effect of $\mathrm{pH}$ on COD removal. 


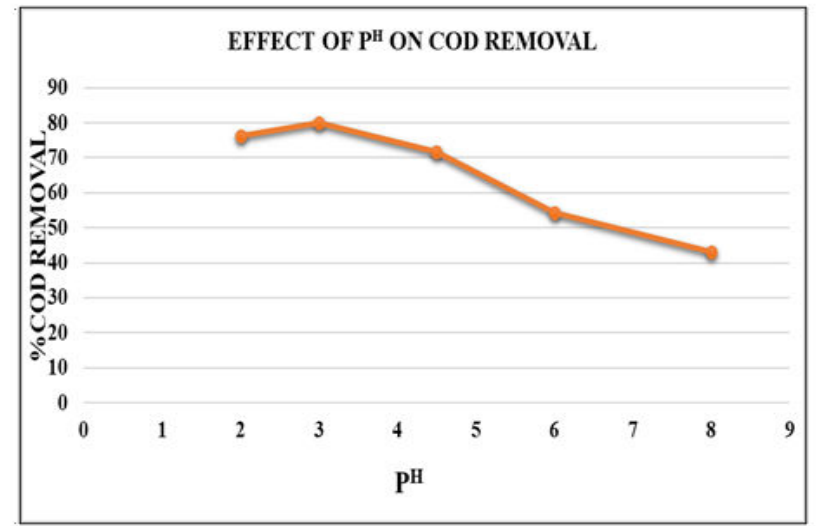

Figure 3: Effect of $\mathrm{pH}$ on COD removal.

Effect of $\mathrm{pH}$ on COD removal by Fenton process is illustrated in Table 3 and Figure 3.

\section{Effect of reaction time on COD removal by Fenton process}

\begin{tabular}{|l|l|l|l|l|}
\hline \multirow{2}{*}{$\mathbf{H}_{2} \mathbf{O}_{2}(\mathrm{ml})$} & \multirow{2}{*}{$\begin{array}{l}\text { Time } \\
(\mathbf{m i n})\end{array}$} & \multicolumn{2}{|c|}{ COD $\mathrm{mg} / \mathrm{I}$} & \multirow{2}{*}{ Removal \% } \\
\cline { 3 - 4 } & & Initial & Final & \\
\hline 3.5 & 10 & 838 & 390.4 & 53.43 \\
3.5 & 20 & 838 & 246.4 & 70.61 \\
3.5 & 30 & 838 & 158.4 & 81.10 \\
3.5 & 45 & 838 & 187.8 & 77.59 \\
3.5 & 60 & 838 & 190.3 & 77.31 \\
3.5 & 80 & 838 & 189.2 & 77.43 \\
\hline
\end{tabular}

Table 4: Effect of Reaction Time on COD removal.

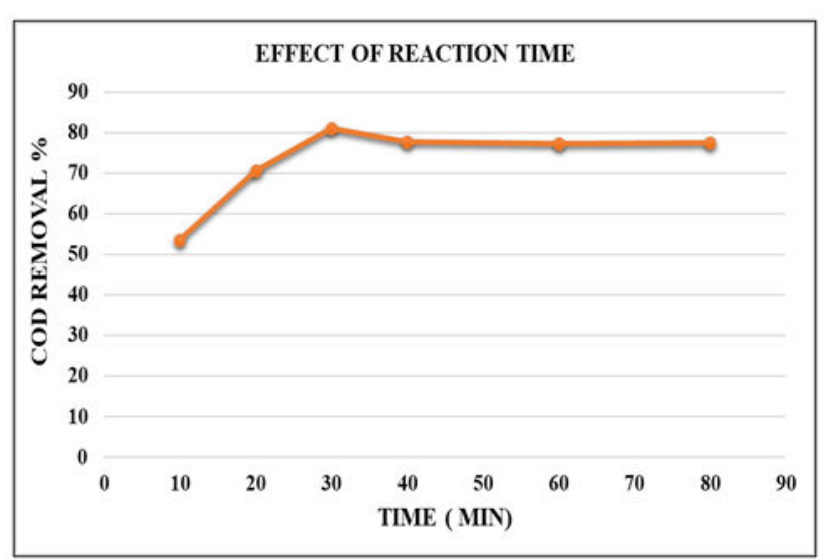

Figure 4: Effect of Reaction Time on COD removal.

Effect of reaction time on COD removal by Fenton process is illustrated in Table 4 and Figure 4.

\section{Conclusions}

The following stage in advanced oxidation process is to make it entirely operative from lab and research scale, and desirable to cost than conventional treatment approaches some deductions that are made, the future research challenges/recommendations are listed as follows

Use of photochemical advanced oxidation process is critical, desired as it is driven by sun light and is a renewable energy source.

There is a research gap among the application of Nano materials from the removal of emerging contaminants from the waste water, and scaling up this process, there are only limited researches taken in this regard, so a possible area of research for the development of ecofriendly friendly degradation process is emphasized

By merging different advanced oxidation processes, removal efficiency of pollutants can be amplified, as an example the use of ultrasound with other advanced oxidation process improves the degradation and these combinations are evidenced to be more cost attractive as equated to the process alone.

As a future challenge, the task of optimizing the process parameter and development of as appropriate reactors is needed to be addressed

For the domestic use and for use in irrigation, water treated with advanced oxidation process or with combinations

\section{References}

1. Woodard and Curran Inc. (2005) Industrial Waste Treatment Handbook. 2nd Edn, USA, pp: 1-532.

2. Mike D (2015) Overview of the process of sewage treatment.

3. Rick F (2016) Organic Strength of Wastewater.

4. Tilley E, Ulrich L, Lüthi C, Zurbrügg C (2011) Compendium of Sanitation Systems and Technologies. 2nd edn.

5. Xiaobai Z (2013) Effect of different plants on azo-dye wastewater bio decolonization.

6. Zhou T, Lim T, Wu X (2011) Sonophotolytic degradation of azo dye reactive black 5 in an ultrasound/UV/ferric system and the roles of different organic ligands. Water Res 45: 2915-2924.

7. Pera-Titus M, García-Molina V, Baños MA, Giménez J, Esplugas S (2004) Degradation of chlorophenols by means of advanced oxidation processes a general review. Appl Catal 47: 219-256.

8. Gogate P, Pandit A (2003) A review of imperative technologies for wastewater treatment I: oxidation technologies at ambient conditions. Adv Environ Res 8: 501-551.

9. Maruf M (2013) Effluent Treatment Plant Process Sequence in Textile Industry.

10. Haber F, Weiss J (1934) The catalytic decomposition of hydrogen peroxide by iron salts. Proc R Soc Lond 147: 332-351.

11. Babuponnusami A, Muthukumar K (2014) A review on Fenton and improvements to the Fenton process for wastewater treatment. J Environ Manage 2: 557-572. 